\title{
The Relationship of Apis mellifera with Exotic and Native Plants in Boulder County, Colorado
}

\author{
Kira Krend and Christina Murphy \\ Department of Ecology and Evolutionary Biology \\ University of Colorado at Boulder \\ Boulder, Colorado 80309 USA
}

Received:May 20, $2003 \quad$ Accepted: August 5, 2003

\begin{abstract}
Since honeybees (Apis mellifera) were introduced to North America in the 1600's, their influence has been profound and widespread. As pollinators, honeybees are extremely valuable economically and are vital to crop pollination. However, their presence has affected native ecosystems, including the plains ecosystem in Colorado. Using recruitment and other unique foraging characteristics, honeybees may be out-competing native pollinators for nectar and pollen resources. Our study was designed to determine if $A$. mellifera has a preference for exotic or native plants. We observed patches of exotic plants and patches of native plants and recorded the type of bee (exotic or native) that visited each flowering head. We also examined data from Kearns and Oliveras (unpublished), which illustrates that invasive plant species are also popular with native bees, and may draw vital pollinators away from native plants. Our results indicate that honeybees prefer to visit exotic invasive plant species to native plants. Consequently, honeybees may contribute to the spread of exotic plant species and the decline of native plant species, reducing biodiversity. Thus, native plants are doubly jeopardized. The invasion of exotic flora and fauna into native ecosystems on the plains of Colorado is part of a worldwide phenomenon of species invasion, and researchers must continue to investigate interspecies relationships to minimize the potential negative effects of invasive species.
\end{abstract}

\section{INTRODUCTION}

The infiltration of exotic species into an area can change ecological processes. Any disturbances to a food web can affect the entire ecosystem. Exotics can often outcompete native species for resources and introduce new diseases and parasites [1]. Three things are clear about exotics: 1) it is impossible to know where an exotic species will become established; 2) when it will happen; 3) and how it will affect an ecosystem [1]. The effects of introduced honeybees on native ecosystems are still unclear; few studies have been done, and those few found differing levels of effect. The purpose of this project was to examine the attractiveness of exotic and native plants to the exotic honeybee, Apis mellifera, by looking at visitation rates in Boulder County, Colorado. Our hypothesis was that $A$. mellifera would visit and pollinate exotic plants more than the native plants of the Front Range.

The honeybee, Apis mellifera, is at the forefront of what ecologists deem a "pollination crisis:" an imbalance of the critical pollination ecosystem of flowering plants [2]. The economic value of flowering plants is enormous, and most angiosperms depend on insect pollinators, such as bees, for sexual reproduction. Changes in the populations of pollinating insects directly affect the plants they pollinate. This shift could potentially have serious consequences for the world's food supply. Part of a worldwide phenomenon of species invasion, $A$. mellifera has been introduced from Eurasia and Africa into most of the rest of the world [3]. Although introduced honeybees may contribute to the decline of native pollinators, and consequently native 
plants, the economic importance of honeybees cannot be denied as they pollinate a significant proportion of flowering plants [4]. Yet some research suggests that honeybees may negatively affect the native biota [5]. Balancing the economic value and ecological consequences of honeybees, as well as many other species, is a complex issue that has yet to be resolved.

\section{a. Study Pollinators}

Apis mellifera is native to Europe, Africa, and northwest Asia. It was first introduced into North America through Jamestown, Virginia, between 1630 and 1663 [5]. Since that time, honeybees have spread to every terrestrial environment in North America and number in the billions. Honeybees often out-compete other pollinators; however, the extent to which they have replaced native species is unclear. Honeybees' success can be attributed to many factors. First, they find flowers quickly and promptly determine if the flowers are worth the time to visit. Secondly, if a good source of nectar is found, honeybees can communicate the location of the flowers to the rest of the hive through recruitment, a tactic not used by most native pollinators. Consequently, honeybees harvest nectar and pollen before native pollinators have a chance [6]. While solitary bees only live for one generation, honeybee colonies are long-lived [6]. Thus, knowledge of flower patch locations can be used by honeybee colonies for generations, while solitary bees must learn these locations independently.

Honeybees are generalists and not faithful to any single plant species. This generality is in contrast to many native pollinators that are specialized visitors of certain plants for nectar and pollen [6]. Additionally, honeybees usually pack their pollen with nectar and saliva, which limits pollen viability and causes less pollen to fall on a flower's stigmatic surface [6]. On some flowers, honeybees are able to collect pollen without ever coming into contact with the flower's stigma, avoiding pollination of the flower. Many ecologists believe that native flower species have not been able to adapt to honeybees' particular method of pollination, because a colony's taste changes from season to season and from area to area [6]. This evidence suggests honeybees may be poor pollinators of some native flora.

While the concept that pollinators are more attracted to plants with which they have co-evolved makes intuitive sense, very few studies have been conducted regarding this association. In residential areas of Berkeley, California, Frankie et al. [7] found that exotic plants had a low attraction for native bees. The authors believed the low attraction may be attributed to horticultural selection where humans have selected for aesthetically pleasing traits, such as showy petals, and not for large amounts of nectar and pollen, resulting in reduced rewards for bees. Additionally, native bees may be less attracted to exotic plants because they did not co-evolve with the exotic plants. Native plants were four times more likely than exotic plants to attract native bees.

Many people think of wax and honey production as the primary economic importance of honeybees. However, Buchmann and Nabhan [4] estimated that honeybee pollination of crops is 50 to 60 percent more valuable than their production of honey and wax. Unfortunately, many ecologists believe that both native pollinators and honeybees are in rapid decline [2]. Some reasons for the drop in honeybee populations include the use of pesticides and infectious parasitism by mites [4]. Also, in regions of the United States that have been invaded by aggressive Africanized bees, many beekeepers have been driven out of business due to rising insurance costs against attacks [4]. This decline could mean lower crop yields, with serious consequences to the world's food supply; one in every three mouthfuls of food eaten is pollinated by animals, including honeybees [4].

Studies that have attempted to look at competition between native bees and $A$. mellifera have reported mixed results. Some studies argue that honeybees change the foraging behavior and population size of native bees [7]. For example, Gross [8] found that native bees were less likely to forage on plants where honeybees are present. Paton [9] determined that native bees of North and South America switch to less profitable flower resources when honeybees were present. Though honeybees are blamed for out-competing 
native pollinators, not pollinating native plants effectively, and increasing the success of weeds, Huryn [3] notes that not much data have been collected to support these accusations.

b. Study Plants

All plants in this study are members of the family Asteraceae. The two plant species native to the Front Range that were included in this study were golden aster (Heterotheca villosa) and gumweed (Grindelia squarrosa). The two exotic species in the study were Canada thistle (Cirsium arvense) and diffuse knapweed (Centaurea diffusa). Data were also examined from (but not analyzed, see Results) sunflowers (Helianthus pumilus, native) and chicory (Cichorium intybus, exotic). Originally a Eurasian immigrant, Canada thistle is considered a pest in towns, gardens, fields, and pastures, and is common in the region. Chicory was also imported from Europe and is common on the plains, often along roads, fields and ditches from July to October [10]. The third exotic plant, diffuse knapweed, will be elaborated on below, as it is a paradigm of an exotic plant species that has invaded an area and may be harming native ecosystems.

Most invasive plant species are not dominant in their natural environment, but easily out-compete native species in environments where they are introduced. For example, Calloway and Aschehoung [11] noted that diffuse knapweed (Centaurea diffusa) has negatively affected many North American plant species, while it has no negative effect on its native plant neighbors in Eastern Europe and Western Asia. Additionally, exotic plant species were imported without their co-evolved insect herbivores and pathogens. Thus, abiotic factors are the only regulators of these plants, and are often not enough to control their population size [12]. Grasslands that have been invaded by exotic tap-rooted weeds such as knapweed have experienced soil and water losses, consequently harming native plants and reducing biodiversity [12].

Clearly, understanding the effects of honeybees on native plants and pollinators is vital to solving the pollination crisis, and more research needs to be conducted. Studies have found differing results with a broad range of implications, which help to illustrate the complexity of plant-pollinator relationships. In our study, we predicted that $A$. mellifera would exhibit a higher visitation to rate to exotic plant species than native plants.

\section{METHODS} Cillosa, Cirsium arvense in the prairie and foothills of Boulder County, $\left(40^{\circ} 00^{\prime} \mathrm{N}\right.$ latitude, and between $105^{\circ} \quad 20^{\prime} \mathrm{W}$ and $105^{\circ} 30^{\prime} \mathrm{W}$ ) Colorado, USA. Each species of flower was observed four to six times. Different patches of flowers were observed on different days for ten-minute periods from July through September 2002. During the study, we observed approximately equal numbers (average 1235 heads) of open flower heads available for pollination on each plant species. We noted whether each visiting bee was a honeybee ( $A$. mellifera) or a native bee, and attempted to identify the native bee visitors to family. We captured representative bees after the observation period was complete, and later identified them to genus. We also recorded the number of flower heads each bee visited during the ten minutes of observation.

To supplement this analysis, we used Kearns and Oliveras' [13] pollination database on bee visitors to grassland plants from their study on the effects of urbanization on pollinator diversity. Their research was conducted on 20 grassland plots in Boulder County, Colorado, USA. We examined the database to determine the number of exotic and native bees that landed on exotic and native plants in the Asteraceae, including the four plants in our study Heterotheca villosa, Centaurea diffusa, Grindelia squarrosa, Cirsium arvense, as well as two more plants, Cichorium intybus, (exotic) and Helianthus pumilus (native).

The data from our study were analyzed with SAS 8e (1999-2001). The procedure used was a logistic analysis with the Williams adjustment to correct for overdispersion. Overdispersion is related to the overall variation between individual plants. 


\section{RESULTS}

Exotic plants were more likely than native plants to be visited by the exotic bee, A. mellifera (Wald Chi square $p=0.0559$; Table 1). With the Williams adjustment applied to correct for overdispersion, the probability of an exotic bee visiting an exotic plant was 7.8 times greater than that of an exotic bee visiting a native plant. However, the number of native bees present was 7-8 times greater than the number of honeybees on both exotic and native plants. We did not observe any interactions between individual bees while visiting the study plants. It was common for a single bee to move between flowering heads in the observed patch while data were being collected.

Unpublished data from an ongoing study by Kearns and Oliveras [13] (Table 3) indicate similar trends to those found in our study. We did not conduct a statistical analysis of these data, since we lumped data from many dates and sites. However, the raw data help illustrate that exotic bees were much more likely to be captured while visiting an exotic plant than while visiting a native plant. The data also show that exotic plants are popular with both native and exotic bees.

Heterotheca villosa (native) 1330 flowering heads observed

\begin{tabular}{|l|l|l|}
\hline & Native bees & Exotic bee (A. mellifera) \\
\hline Total number of visiting bees & 48 & 2 \\
\hline Total landings on flowering heads & 547 & 8 \\
\hline
\end{tabular}

Grindelia squarrosa (native) 1090 flowering heads observed

\begin{tabular}{|l|l|l|}
\hline & Native bees & Exotic bee (A. mellifera) \\
\hline Total number of visiting bees & 96 & 0 \\
\hline Total landings on flower heads & 419 & 0 \\
\hline
\end{tabular}

Cirsium arvense (exotic) 1250 flowering heads observed

\begin{tabular}{|l|l|l|}
\hline & Native bees & Exotic bee $($ A. mellifera) \\
\hline Total number of visiting bees & 93 & 13 \\
\hline Total landings on flower heads & 195 & 32 \\
\hline
\end{tabular}

Centaurea diffusa (exotic) 1270 flowering heads observed

\begin{tabular}{|l|l|l|}
\hline & Native bees & Exotic bee $($ A. mellifera) \\
\hline Total number of visiting bees & 73 & 10 \\
\hline Total landings on flower heads & 407 & 53 \\
\hline
\end{tabular}

Table 1. Total number of bees and bee landings observed on study plants during data collection periods. Statistical analysis was performed on the total number of landings on each study plant. Data are from the present study (Krend and Murphy). 


\section{DISCUSSION}

The data from our study indicate that $A$. mellifera is much more likely to visit an exotic study plant than a native study plant. Exotic plants in the study also appear to be utilized by native bees. Unpublished data from Kearns and Oliveras [13] seem to indicate a similar trend. While our study was short-term, collected over a period of three months, Kearns and Oliveras' data are being collected over three years. Our study focused on observing bees on flowering heads, while Kearns and Oliveras' study involves collecting the bees. However, both studies indicate the above trends. The repercussions of these trends could potentially be widespread for both native plants and native pollinators. The reproductive success of exotic plants, due to pollination by exotic bees, may displace native plants, consequently reducing biodiversity. Additionally, if pollinators visit an invasive plant species more frequently than a native plant, indigenous plants are left with fewer pollinators to facilitate sexual reproduction.

In the United States, information on the abundance and diversity of native bee species before the introduction of honeybees is almost non-existent. This lack of information makes the effects of honeybees difficult to assess, and few studies have addressed this question. In Australia, where honeybees were introduced only in the last 150 years, more studies have been conducted. The sources of nectar and pollen used by $A$. mellifera in Australia overlap with those of native bird and bee pollinators, resulting in competition.

One Australian study showed that honeybees begin foraging in the early morning when most flowers have the most resources, while native Australian bees are most active in the middle of the day [9]. Another study illustrated that honeybees temporarily reduced the foraging success of native bees by depleting mutual resources [14]. Honeybees also out-competed native bees by foraging over greater areas, and by their ability to move their colonies [5].

At least one study indicated that honeybees affected the New Holland honeyeater (Phylidonyris novaehollandiae) in Australia [9]. This study estimated that honeybees removed more than $90 \%$ of the

\begin{tabular}{|l|l|}
\hline Plant species & $\begin{array}{l}\text { Genera of } \\
\text { native bees } \\
\text { observed }\end{array}$ \\
\hline $\begin{array}{l}\text { Grindelia squarrosa } \\
\text { (native) }\end{array}$ & $\begin{array}{l}\text { Agapostemon } \\
\text { Lasioglossum } \\
\text { Megachile } \\
\text { Melissodes } \\
\text { Hoplitis } \\
\text { Andrena } \\
\text { Dianthidium } \\
\text { Anthidum } \\
\text { Bombus }\end{array}$ \\
\hline $\begin{array}{l}\text { Heterotheca } \\
\text { villosa } \\
\text { (native) }\end{array}$ & $\begin{array}{l}\text { Hylaeus } \\
\text { Agapostemon } \\
\text { Melissodes } \\
\text { Halictus } \\
\text { Megachile } \\
\text { Heterosaurus } \\
\text { Panurginus }\end{array}$ \\
\hline $\begin{array}{l}\text { Centaurea } \\
\text { diffusa } \\
\text { (exotic) }\end{array}$ & $\begin{array}{l}\text { Ceratina } \\
\text { Dialictus } \\
\text { (exotic) }\end{array}$ \\
\hline $\begin{array}{l}\text { Mense } \\
\text { Colletes } \\
\text { Hylaeus } \\
\text { Dialictus } \\
\text { Andrena } \\
\text { Halictus } \\
\text { Svastra }\end{array}$ \\
\hline $\begin{array}{l}\text { Sphecodes } \\
\text { Lasioglossum }\end{array}$ \\
\hline
\end{tabular}

Table 2. Genera of native bees observed on native and exotic plant species. The only exotic bee observed was $A$. mellifera. Data are from the present study (Krend and Murphy).

nectar from bird-pollinated flowers. Also, New Holland honeyeaters were much less likely to visit flowers when the honeybee population was high, and avoided flowers where honeybees were present. When honeybees replace native honeyeaters as plant pollinators, plant fitness may decrease. On one Australian plant, Callistemon rugulosus (Myrtaceae), nectar harvesting 


\begin{tabular}{|l|c|c|}
\hline $\begin{array}{l}\text { Plant } \\
\text { species }\end{array}$ & $\begin{array}{l}\text { Number } \\
\text { of native } \\
\text { bees }\end{array}$ & $\begin{array}{l}\text { Number of } \\
\text { A. mellifera } \\
\text { (exotic) }\end{array}$ \\
\hline $\begin{array}{l}\text { Heterotheca } \\
\text { villosa } \\
\text { (native) }\end{array}$ & 95 & 1 \\
\hline $\begin{array}{l}\text { Grindelia } \\
\text { squarrosa } \\
\text { (native) }\end{array}$ & 10 & 0 \\
\hline $\begin{array}{l}\text { Helianthus } \\
\text { pumilus } \\
\text { (native) }\end{array}$ & 50 & 0 \\
\hline $\begin{array}{l}\text { Centaurea } \\
\text { diffusa } \\
\text { (exotic) }\end{array}$ & 39 & 33 \\
\hline $\begin{array}{l}\text { Cirsium } \\
\text { arvense } \\
\text { (exotic) }\end{array}$ & 11 & 14 \\
\hline $\begin{array}{l}\text { Cichorium } \\
\text { intybus } \\
\text { (exotic) }\end{array}$ & 19 & 11 \\
\hline
\end{tabular}

Table 3. The numbers of native and exotic (A. mellifera) bees collected on native and exotic plants. Data are from Kearns and Oliveras [13].

honeybees only struck the stigma on $4.4 \%$ of visits, while its native pollinator, the New Holland honeyeater, struck the stigma more than $50 \%$ of the time [9]. Presently, researchers do not know if a similar trend is occurring with native bees and honeybees in the United States.

Despite negative effects, removing honeybees completely may be detrimental to native plants that have lost their natural pollinators or are inadequately pollinated by the native fauna. For example, Orthrosanthus multiflorus (Iridaceae) is only in flower for a single day. Honeybees were able to pollinate $O$. multiflorus effectively, while native pollinators were not always as efficient [9]. Thus, honeybees are effective pollinators for some native plants such as $O$. multiflorus but certainly not all flowering plants, as illustrated by its low pollination rate of Callistemon rugulosus [9]. On the Colorado prairie, more research needs to be conducted on the pollination efficiency of honeybees on individual plant species, both native and exotic.

Although our study found that honeybees visit exotic plants more than native plants, many more native bees were observed overall (on both exotic and native study plants) than honeybees. As such, native bees may also be contributing to the spread of exotic plants. However, the influence of any species of bee on the success of invasive plants may be overrated because plants' ability to reproduce asexually. According to a study by Huryn and Moller [15], honeybees might not play a large role in the overall success of invasive plants since most problematic weeds tend to have plastic reproduction, such as selfpollination, unspecialized pollination, high germination rates, specialized seed dispersal, or vegetative spread. Huryn and Moller [15] found that in New Zealand, only one out of 29 problem weeds studied was 'highly influenced' by honeybees. Thus, this study indicated that most weeds would probably still be successful without honeybees, and the influence of $A$. mellifera is probably minimal for most problem weeds. Researchers have not yet determined how successful invasive species such as knapweed would be on the prairie without the facilitation of sexual reproduction by honeybees and other bees.

The influence of $A$. mellifera on native pollinators is complex. Honeybees' system of recruitment and other unique traits may help them out-compete native pollinators. Since honeybees target exotic plants, native bees may still have plenty of nectar and pollen available for consumption from native plants. However, native pollinators might have their own interspecific competition on native plants, causing some native bees to move to exotic plants and compete with honeybees. Whether honeybees are actually taking away resources from native bees and forcing them to visit fewer plants and/or plants with depleted nectar and pollen has yet to be conclusively determined.

From studies in the United States, as well as Australia and New Zealand, $A$. mellifera is clearly affecting native ecosystems. Yet how detrimental $A$. mellifera is in specific situations remains to be determined. While researchers do not 
yet know if the presence of honeybees causes the decrease in native bees present, honeybees are clearly affecting the pollination of plants on the prairie. The introduction of honeybees to the North American continent has led to both detrimental and beneficial consequences. Although they could be facilitating the spread of exotic plants, and possibly causing the decline of native pollinators, the contribution of the honeybee to the food supply through crop pollination is of vital economic importance [4].

The introductions of invasive plants, such as diffuse knapweed, and of animals, such as the honeybee, have many implications to the native plains ecosystem. Ecologists recognize these introductions as part of a worldwide phenomenon of exotic species invasion. The potential consequences of exotic introductions are shifts in the delicate relationships between species in the native ecosystems. Though nearly all ecosystems on Earth have already experienced invasion of exotic species, research must continue in order to understand intricate interspecies relationships to help minimize the potential negative effects of invasive species.

\section{ACKNOWLEDGEMENTS}

We would like to thank Carol Kearns and Diana Oliveras of the Baker Residential Academic Program, University of Colorado at Boulder, for their guidance and support. We would also like to thank Bill Oliver for his assistance with statistical questions, Pablo Weaver for assisting in the editing process, and three anonymous reviewers for providing constructive comments on drafts of this paper. The Undergraduate Research Opportunities Program at the University of Colorado at Boulder funded this research.

\section{REFERENCES}

1. Bright, C. 1995. Bio-invasions: the spread of exotic species. World Watch. July/Aug:10-18.

2. Kearns, C.A., D.W. Inouye and N.M. Waser. 1998. Endangered mutualisms: the conservation of plant-pollinator interactions. Annual Reviews of Ecology and Systematics 29:83-112.
3. Huryn, V.M. 1997. Ecological impacts of introduced honey bees. The Quarterly Review of Biology 72:275-297.

4. Buchmann, S.L. and G.P. Nabhan. 1996. The pollination crisis: the plight of the honeybee and the decline of other pollinators imperils future harvests. The Sciences. 36:22-28

5. Hubbell, S. 1997. Trouble with Honeybees. Natural History. 106:3243.

6. Westerkamp, C. 1991. Honeybees are poor pollinators-why? Plant Systematics and Evolution 177:71-75.

7. Frankie, G.W., R.W. Thorp, M.H. Schindler, B. Ertter and M. Przybylski. 2002. Bees in Berkeley? Fremontia. 30:50-58.

8. Gross, C.L. 2001. The effect of introduced honeybees on native bee visitation and fruit-set in Dillwynia juniperina (Fabaceae) in a fragmented ecosystem. Biological Conservation 102:89-95.

9. Paton, D.C. 1993. Honeybees in the Australian environment. Bioscience 43:95-103.

10. Guennel, G.K. 1995. Guide to Colorado Wildflowers. Westcliffe Publishers, Inc. Englewood, Colorado.

11. Callaway, R.M. and E.T. Aschehoung. 2000. Invasive plants versus their new and old neighbors: a mechanism for exotic invasion. Science 290:521-523.

12. Beck, K.G. 1994. How do weeds affect us all? Abstract, Leafy Spurge Symposium. Bozeman, Montana; July 26-29, 1994. http://www.team.ars.usda. gov/ symposium/1994/one.html. Accessed 13 July 2002.

13. Kearns, C. and D. Olivias (private communication)

14. Sugden, E.A. and G.H. Pyke. 1991. Effects of honey bees on colonies of Exoneura asimillima, and Australian native bee. Australian Journal of Ecology 16:171-181.

15. Huryn, V.M. and H. Moller. 1995. An assessment of the contribution of honey bees to weed reproduction in New Zealand protected natural areas. New Zealand Journal of Ecology 19:111121. 


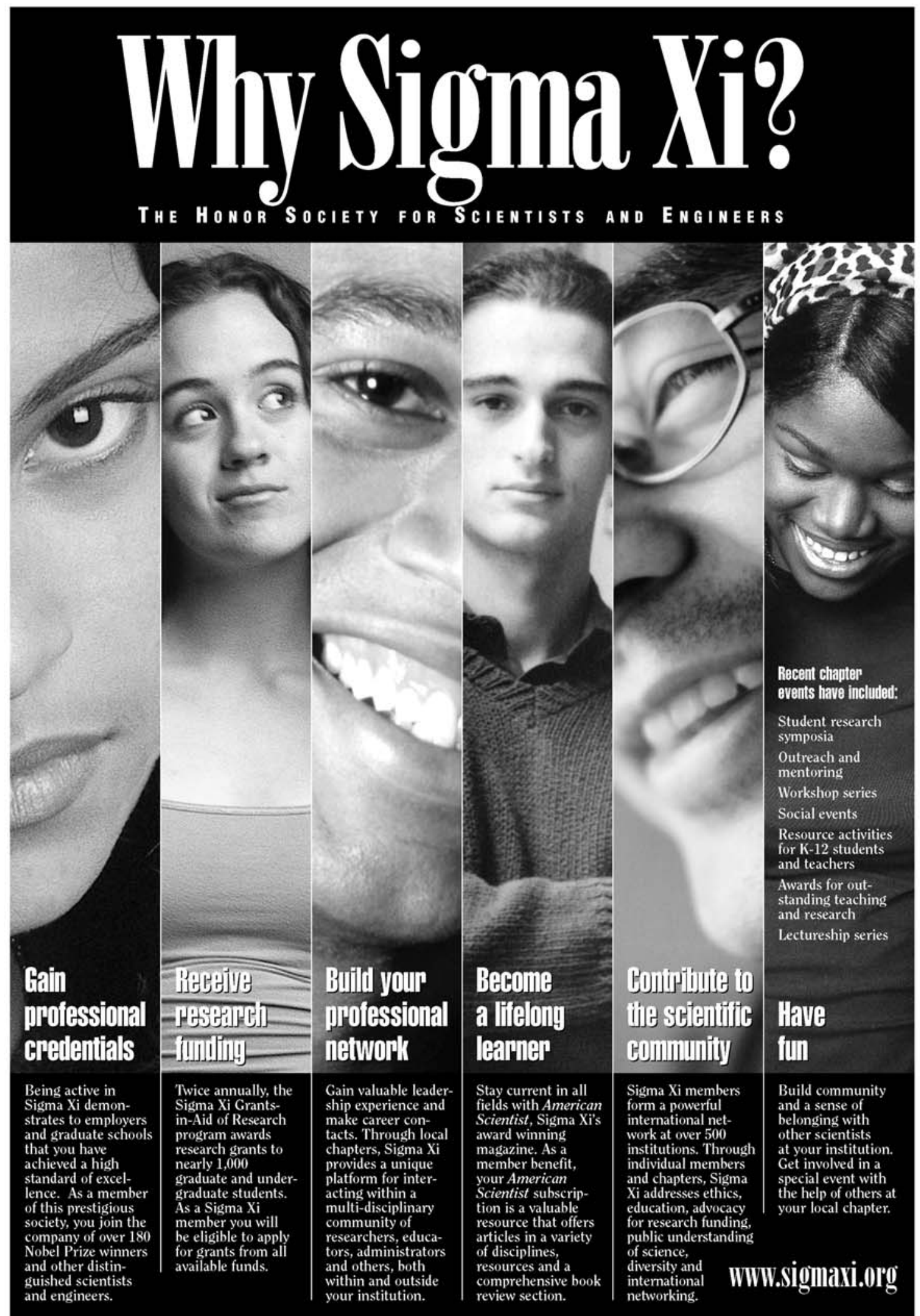

Sigma Xi, The Scientific Research Society • 88 Alexander Drive • P.O. Box 13875 • Research Triangle Park, NC 27709 • 818-549-4891 • 800-243-6534 